\title{
Correction: miR-424-5p promotes proliferation of gastric cancer by targeting Smad3 through TGF- $\beta$ signaling pathway
}

\section{Song Wei, Qing Li, Zheng Li, Linjun Wang, Lei Zhang, Zekuan Xu}

Copyright: Wei, et al. This is an open-access article distributed under the terms of the Creative Commons Attribution License (CC-BY), which permits unrestricted use, distribution, and reproduction in any medium, provided the original author and source are credited.

Present: The current funding acknowledgement information is incorrect.

Correct: The proper funding information appears below. The authors sincerely apologize for this oversight.

\section{FUNDING}

This work was supported by the National Natural Science Foundation Project of International Cooperation (NSFC-NIH, 81361120398); the National Natural Science Foundation of China (81272712, 81572362); the Priority Academic Program Development of Jiangsu Higher Education Institutions (PAPD, JX10231801); the Program for Development of Innovative Research Team in the First Affiliated Hospital of NJMU; 333 Project of Jiangsu Province (BRA2015474).

Original article: Oncotarget. 2016; 7:75185-75196. doi: 10.18632/oncotarget.12092 